\title{
The Outcome of Using Different Techniques for Centralization of the Nasal Tip
}

\author{
Mohamed S. Aly ${ }^{1}$, Bashayr A. Bajaber ${ }^{2}$, Ghayda'a S. Hazzazi ${ }^{3}$, Haneen A. Abba ${ }^{4}$, \\ Rahaf Y. Alahmadi ${ }^{5}$, Sara M. Aletyani ${ }^{6}$, Shouq N. Alduayah ${ }^{7}$ \\ ${ }^{1}$ Consultant Otolaryngology - Head and Neck Surgery, King Abdullah Medical City, Mecca, KSA \\ 2, 3, 4, 5, 6, 7 Medical Intern, Umm Al-Qura'a University, Mecca, KSA
}

\begin{abstract}
Purpose: }}$ Tip surgery in rhinoplasty is one of the most challenging procedures that evolve the surgeon to narrow the interdomal distance and centralize the nasal tip ${ }^{\perp}$. This can be approached by different techniques; either closed or opened techniques (Extra-corporeal, Open book, Combined and Septal Extension and Extended Spreader graft techniques). Due to lack of information in the literature, we decided to compare the results of the five techniques and choose the most suitable one for the Middle Eastern population and focus on it in our practice. Method: Retrospective review was performed on 134 patients who underwent septorhinoplasty at the department of Otolaryngology, Head and Neck Surgery at King Abdullah Medical City, Mecca, Saudi Arabia. 16 patients underwent septo-rhinoplasty with closed technique, 46 with Combined technique, 46 with Open book technique, 11 with Extracorporeal technique and 17 patients with Septal Extension and Extended Spreader Graft technique. Patients' data were collected and analyzed to compare the results of the five techniques after IRB approval. Results: Open book technique gave the best results based on the narrowing of the interdomal distance and correction the angle of nasal tip deviation, including a score of patient's satisfaction with the aesthetic look and breathing pre and post-operatively. Conclusion: Opened techniques give good post-operative results, but Open book technique showed to be the best among all techniques used to correct the deviation of the nasal tip.
\end{abstract}

Keywords: Deviated and broadNose; Rhinoplasty; Septo-rhinoplasty; Aesthetic look; Nasal function

\section{Introduction}

The usual aim of nasal tip surgery is to narrow the interdomal distance and to centralize the nasal tip with the vertical facial line and to balance the angle between the tip and the vertical facial line ${ }^{1}$. One of the most important objectives is to preserve and improve the structural supportive mechanism of the nose, considering its function and its dynamic movement during inhalation and exhalation $^{2}$.

This can be approached by different techniques, either closed or open techniques (Open book technique, combined technique (closed and open approach), Septal Extension and Extended Spreader graft technique, Extra-corporeal technique.

Open book, combined, Septal Extension and Extended Spreader graft techniques share the same principals although there are some minimal variations between them; that's why their postoperative results are approximately the same.

Putting in mind that in the Middle East region, patients tend to have thicker skin, numerous polio sebaceous glands with under projecting tip and hump nose, the widening of the osseous and cartilaginous vaults in the middle third with amorphous and hanging nasal tip.

There are a variety of surgical techniques for septorhinoplasty, and no particular method is applicable to all patients. It's on the surgeon to choose the best that ends up to a better possible outcome.

\section{Subjects and Methods}

\subsection{Study Design}

We designed Retrospective study which was performed on one hundred and forty patients who underwent septorhinoplasty at the department of Otolaryngology, Head and Neck Surgery at King Abdullah Medical City, Mecca, Saudi Arabia. All operations were done by Dr. Mohamed S. Aly, Consultant Otolaryngology.

Patients' data were collected and analyzed to compare the results of the five techniques after IRB approval. We included all patients attending ENT clinic diagnosed with nasal obstruction, nasal tip deformity and broad nose. Exclusion criteria were any patient who is younger than 18 years $^{3}$.

\subsection{Ethical Approval}

The protocol of this study was approved by the research center at King Abdullah Medical City.A written informed consent was obtained from each patient for the operation, photos, pre and post-operative complications. All patients' data were collected from their files and analyzed to compare the results of the five techniques.

\subsection{Variables}

Pre-operative evaluations: Screen Calipers program (version: 3.3) was used to measure the interdomal distance, while Screen Protractor (version: 3.3) was used to measure the angle of nasal tip deviation before operation, also a score of patients' satisfaction of the nasal aesthetic look and breathing was recorded. A complete physical examination 


\section{International Journal of Science and Research (IJSR) \\ ISSN (Online) : 2319-7064}

Index Copernicus Value (2015) : 78.96 | Impact Factor (2015) : 6.391

was performed by a physician in-charge, and positive findings were reflected into the sheets.

Regarding the Photographic documentation: Full-face views: (Frontal, Dead Lateral: right and left, Lateral Oblique: right and left, Basal, Dynamic view) were captured once before the surgery, after the surgery at least one yearand at a follow-up appointment by Nikon camera 3100. The values required before and after the operation for nasal tip deviation $\&$ interdomal distance measurements were obtained from the photos after fixation of the interpapillary distance to $(5 \mathrm{c.m})$ through computer analysis.

Patient's satisfaction rates: At the end of the evaluation, patients were asked to determine their satisfaction rates with their aesthetic look and functional out-comes, separately; for each of them they had to choose one score of the following: (1=strongly unsatisfied, $2=$ unsatisfied, $3=$ undecided, $4=$ satisfied, $5=$ strongly satisfied) ${ }^{4}$.

\subsection{Method of Surgery}

All of the patients who were included in the study underwent some other surgical procedures beside the correction of the broad and deviated nose, like the correction of the hump nose if it was present, dorsal nasal irregularities, reduction of the size of turbinate if there is nasal turbinate hypertrophy and reduction of the flare ala by alar wedge resection. All procedures were performed by the author under general anesthesia. Moreover, antibiotic and analgesics was given to all patients post operatively. Subsequently, their nasal splints and sutures were removed after seven days 5 .

Open Book Technique (Dallas) :

- Transclumellar and bilateral infracartilegenous.

- Soft tissue elevation and dissection of lower lateral cartilage.

- Septal reconstruction and cartilage graft harvest.

- Upper lateral graft tension - spanning sutures.

- Spreader graft (if indicated)

- Cephalic trim (if indicated)

- Establishing final tip projection (clumellar strut graft - tip suturing techniques, tip, grafts)

- Fixation of the caudal septum to the anterior nasal spine by drill hole.

Combined approach technique (Danial) :

1) Goodmon's original involved $V$ with wings

2) Standard infracartilaginous incision deep consists of three parts: crural, dome and columella.

3) Columella to tip exposure.

4) Bidirectional exposure

5) Septal exposure and Extramucosal tunnels

- The trans fixation approach: a full length Trans fixation.

- Incision is is made $2-3 \mathrm{~mm}$ back from the caudal borders.

6) Extra mucosal tunnels: for protection of the underlying mucosa from distribution and scaring.

7) Tip analysis symmetrical rim strips:

8) Symmetrical rim strips: leave6 $\mathrm{mm}$ width and remove excess part of the lower lateral cartilage.
9) Caudal septum and anterior nasal spine 2-3 $\mathrm{mm}$ resection of the caudal septal part for shortening of the nose.

10) Grafting: by columellar strut.

11) Caudal septal relocation suture to anterior nasal spine through the hole drilled through the A.N.S polydioxarone suture (PDS) from the non-deviated side, the knot is the tied on the non-deviated side of the A.N.S.

Septal extension spreader extended graft (Toriumi approach) :

This technique like open book technique but using caudal extension graft which was harvested from the septum and usually rectangular.

Medial Couse are sutured to the coudal margin of the extension to prevent shifting of the graft

Spreader extension graft fix the septal extension graft

Interdomal and dome birding sutures, tip grafts, and crushed cartilage on lay grafts

\section{Extracorporeal technique:}

In cases of severely nose

Requires complete separation cartilage from all its attachments, once removed the deviation can be corrected.

Then once the cartilage has been reshaped and sutured onto the pds it is reinserted into the nose

Suture to the anterior nasal spire as a first point of fixation. The second point suture the septum with upper lateral cartilage with one mattress suture, the third point of fixation is with transseptal mattress (quilting) suture.

- The $4^{\text {th }}$ point of fixation : fix the septum with bony nasal septum by cress cross suture or transosseous transcartilagenous suture

- The tip can be addressed as indiated, and closure is carried out in the standard fashion

\section{Close technique}

- Transcartilagenous incision in the upper lateral cartilage \& a full length transfixation incision

- Exposure of the anterior septal angle

- Dissection sub smas layer, the dorsum of the nose exposed \& using endoscopy for oetcotomy, septoplasty, \& separation of the septum from the upper fonteral cartilage for centralization of the nose, suturing the caudal part of the septum to anterior nasal spine for Tip centralization.

\subsection{Statistical Method}

Pre and post-operative deviation angles and interdomal distances were extracted from patient's photos and analyzed, to determine the interrelationship of surgical method with the aesthetic look and functional outcomes. Satisfaction degrees rated by patients in follow-up visits. Data were analyzed by t-Test and using SPSS (11.5). P values less than 0.05 were considered as significant.

\section{Results}

One hundred and forty patients were enrolled into the study, forty-seven of them were females and eighty-seven of them 


\section{International Journal of Science and Research (IJSR) \\ ISSN (Online) : 2319-7064}

Index Copernicus Value (2015) : 78.96 | Impact Factor (2015) : 6.391

were males, there ages were more than eighteen years old. Only six patients were excluded due to lack of postoperative data.

We had one hundred and eighteen patients who underwent open septorhinoplasty (Eleven patients with Extra-corporeal technique, seventeen patients with Septal Extension and Extended Spreader graft technique, forty-six patients with combined technique and Forty-six patients with Open book technique) and fourteen patients had a closed technique.

Chief complain included either deviated nasal tip (traumatic) or broad nose. Patient's data were collected from their files and analyzed to compare the results of the five techniques.

A criterion of comparison was based on:

- Interdomal distance before and after operation.

- Deviation of the nasal tip before and after operation.

- Patients' aesthetic and breathing satisfaction before and afteroperation:Each patient had to choose a score (from 1$5)$.

\subsection{Septo-rhinoplasty Outcomes in Closed Technique:}

The mean value for interdomal distance before the operation was 1.4 which was postoperatively reduced to $1.3(\mathrm{p}$ value $=$

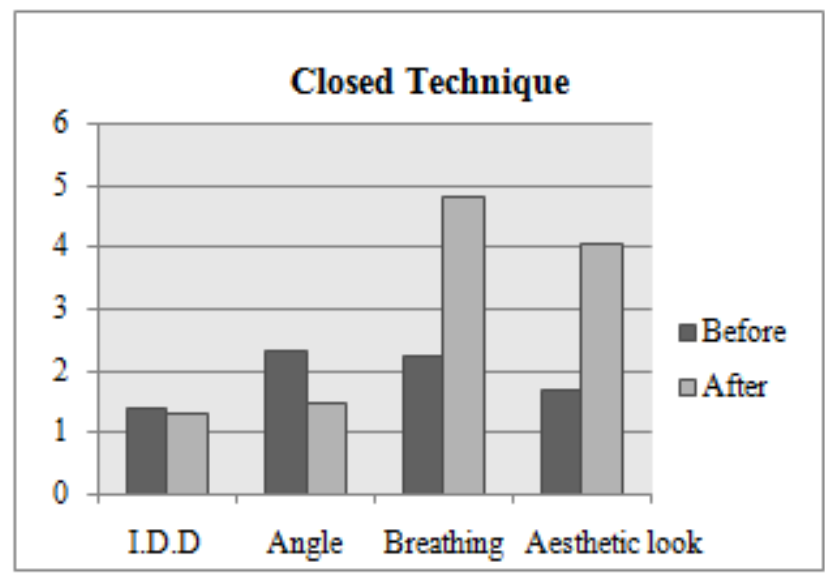

I.D.D: Interdomal distance

\subsection{Interdomal Distance Pre and Post Operatively:}

According to the statistics; there is no significant difference between closed and opened approaches in narrowing the interdomal distance. But Septal Extension and Extended Spreader graft and Extra-corporeal techniques gave the best result.

\begin{tabular}{|c|c|c|c|}
\hline Techniques & $\begin{array}{c}\text { Mean value } \\
\text { preoperative }\end{array}$ & $\begin{array}{c}\text { Mean value } \\
\text { postoperative }\end{array}$ & $\mathrm{p}$ value \\
\hline Closed, $\mathrm{n}=14$ & 1.4 & 1.3 & .04 \\
\hline Open book, $\mathrm{n}=46$ & 1.4 & 1.3 & .05 \\
\hline Combined, $\mathrm{n}=46$ & 1.4 & 1.3 & .00 \\
\hline $\begin{array}{c}\text { Septal Extension and } \\
\text { Extended Spreader } \\
\text { graft, } \mathrm{n}=17\end{array}$ & 1.1 & 0.10 & .00 \\
\hline Extra-corporeal, $\mathrm{n}=11$ & 1.2 & 0.10 & 0.2 \\
\hline
\end{tabular}

(Interdomal distance pre and post operatively)
0.041), regarding to the correction of nasal tip deviation the mean value before the operation was 2.3 which was reduced to 1.5 postoperatively $(\mathrm{p}$ value $=0.00$ ) .

The score of patients' aesthetic and breathing satisfaction before the operation they were 1.7, 2.3which increased postoperatively to $4.1,4.8$ respectively $(\mathrm{p}$ value $=.001),(\mathrm{p}$ value $=.001)$.

\subsection{Septo-rhinoplasty Outcomes in Open Techniques:}

In this group the mean value for interdomal distance was 1.4 which was decreased postoperatively to $1.2(\mathrm{p}$ value $=0.00)$, regarding the correction of nasal tip deviation the mean value preoperatively was 2.2 and postoperatively was 1.4 (p value $=0.00)$.

Patients' aesthetic and breathing satisfaction before the operation were $1.9,2.7$ which were increased to $4.1,4.7$ respectively $(\mathrm{p}$ value $=.00),(\mathrm{p}$ value $=.00)$.

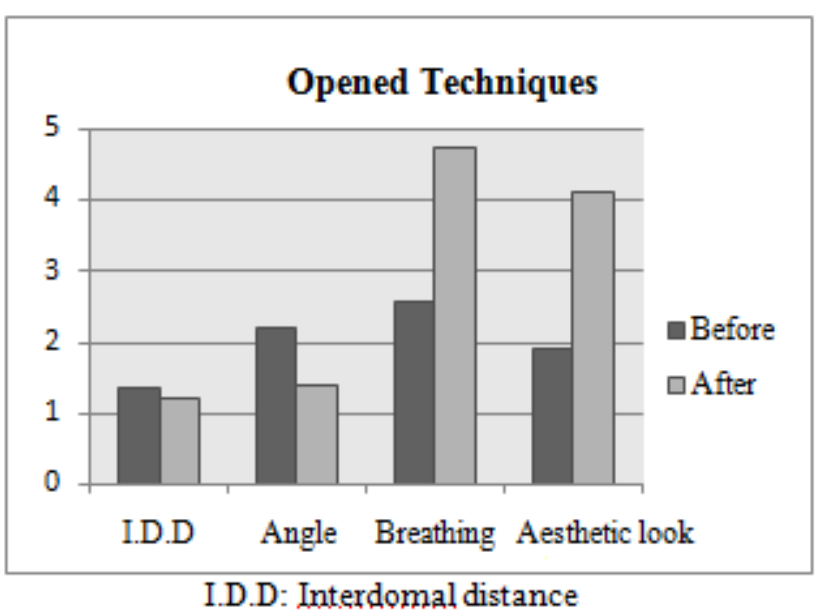

\subsection{Angle of Nasal Tip Deviation Pre and Post Operatively:}

Both closed and open septorhinoplasty had corrected the deviated angles, But Open book technique gave the best results among all of them.

\begin{tabular}{|c|c|c|c|}
\hline Techniques & $\begin{array}{c}\text { Mean value } \\
\text { preoperative }\end{array}$ & $\begin{array}{c}\text { Mean value } \\
\text { postoperative }\end{array}$ & $\mathrm{p}$ value \\
\hline Closed, $\mathrm{n}=14$ & $\mathbf{2 . 3}$ & $\mathbf{1 . 5}$ & $\mathbf{. 0 0}$ \\
\hline Open book, $\mathrm{n}=46$ & $\mathbf{2 . 1}$ & $\mathbf{1 . 2}$ & $\mathbf{. 0 0}$ \\
\hline Combined, $\mathrm{n}=46$ & $\mathbf{2 . 4}$ & $\mathbf{1 . 6}$ & $\mathbf{. 0 0}$ \\
\hline $\begin{array}{c}\text { Septal Extension and Extended } \\
\text { Spreader graft, } \mathrm{n}=17\end{array}$ & $\mathbf{2 . 0}$ & $\mathbf{1 . 3}$ & $\mathbf{. 0 0}$ \\
\hline Extra-corporeal, $\mathrm{n}=11$ & $\mathbf{2 . 0}$ & $\mathbf{1 . 4}$ & $\mathbf{. 0 1}$ \\
\hline
\end{tabular}

(Angle of nasal tip deviation pre and post operatively) 


\section{International Journal of Science and Research (IJSR) \\ ISSN (Online) : 2319-7064}

Index Copernicus Value (2015) : 78.96 | Impact Factor (2015) : 6.391

3.5 Patients' Aesthetic and Breathing Satisfaction Pre and Post Operatively:

All patients' post-operative satisfaction with their aesthetic look and functional outcomes were taken in their last followup visit (at least one year after the operation) and they were significantly satisfied. Other surgical interventions were made in order to improve the function of the nose like: septoplasty, turbinoplasty and alar wedge resection.

\begin{tabular}{|c|c|c|c|}
\hline Techniques & $\begin{array}{c}\text { Mean value } \\
\text { preoperative }\end{array}$ & $\begin{array}{c}\text { Mean value } \\
\text { postoperative }\end{array}$ & $\mathrm{p}$ value \\
\hline Closed, $\mathrm{n}=14$ & 2.5 & 4.8 & .001 \\
\hline Open book, $\mathrm{n}=46$ & 2.7 & 4.8 & .00 \\
\hline Combined, $\mathrm{n}=46$ & 2.4 & 4.8 & .00 \\
\hline $\begin{array}{c}\text { Septal Extension and Extended } \\
\text { Spreader graft, } \mathrm{n}=17\end{array}$ & 3.1 & 4.4 & .004 \\
\hline Extra-corporeal, $\mathrm{n}=11$ & 1.8 & 4.7 & .005 \\
\hline
\end{tabular}

(Patients' breathing satisfaction pre and post operatively)

\begin{tabular}{|c|c|c|c|}
\hline Techniques & $\begin{array}{c}\text { Mean value } \\
\text { preoperative }\end{array}$ & $\begin{array}{c}\text { Mean value } \\
\text { postoperative }\end{array}$ & $\mathrm{p}$ value \\
\hline Closed, $\mathrm{n}=14$ & 1.7 & 4.1 & .001 \\
\hline Open book, $\mathrm{n}=46$ & 1.8 & 4.1 & .00 \\
\hline Combined, $\mathrm{n}=46$ & 2.1 & 4.1 & .00 \\
\hline $\begin{array}{c}\text { Septal Extension and Extended } \\
\text { Spreader graft, } \mathrm{n}=17\end{array}$ & 1.7 & 4 & .00 \\
\hline Extra-corporeal, $\mathrm{n}=11$ & 2.1 & 4.1 & .004 \\
\hline
\end{tabular}

(Patients' aesthetic satisfaction pre and post operatively)

\subsection{Complications}

Open surgery precipitated in minor post-operative complications including dorsal irregularities in 7 patients and saddle nose in 5 patients. A major complication was septal perforation and bleeding in one patient ${ }^{6}$.

\section{Discussion}

Septorhinoplasty is a term used to describe a variety of surgical techniques that are performed in order to change the aesthetic nasal view and generally to enhance the nasal function, since nasal obstruction and nasal septum deviation are considered the commonest presentations patients come to the ENT clinic complaining of. Up to $85.1 \%$ have problems with nasal function and mainly obstructive symptoms, while $14.9 \%$ have aesthetic look issues. Also $6 \%$ of patients have sinusitis as an associated symptom, 45.5\% have headache, and $43.3 \%$ have hyposomia. These problems can be corrected using either a closed rhinoplasty where the surgical access to the nasal structures is gained endonasaly, or an open rihnoplasty where incisions are placed outside the nostrils (externally). They are performed to patients who have a nasal condition that is genetic in origin or a condition that is caused by a trauma to nose and also to correct a nasal deformity caused by a previous unsuccessful septoplasty.

Closed techniques have variety of advantages because there is less need for surgical dissection, consequently postoperative edema is less. Using those causes less scarring to the skin and the nose will take shorter time to heal. In the other hand, open techniques provide a direct observation of the nasal inner structures making it easier to work on the nasal tip, septum and dorsum.
Tip Surgery:

- Clumellar strut suture

- Domal creation suture

- Interdomal suture

- Tip position suture

- Add-on tip refinement grafts

Both closed and open techniques have achieved high satisfaction rates scored by patients. But opened techniques were only better than closed approach by a very limited score: Mean difference of Interdomal distance: 0.09, Mean difference of angle deviation: 0.09, Mean difference in satisfaction of breathing post-operatively: 0.08 . Open book (Dallas) technique gave the best results in the correction of the angle of nasal tip deviation with highest satisfaction rate regarding to aesthetic look. Only $3.8 \%$ of patients have sever deformity and deviation so they need another operation. While Septal Extension and Extended Spreader graft (Toriumi) and Extra-corporeal (Gubisch) techniques gave best result in narrowing the interdomal distance because our experience and learning curve were highly improved. and regarding to patient breathing satisfaction Extra-corporeal technique gave the highest rate because it was performed for more severely complicated deformities.

However, most of surgeons prefer open approach for cases of sever deviated nasal septum and some others still use closed approach for minor cases since it takes shorter period of time to perform and for the patient to heal $(7,8,9,10,11,12)$.

\section{Conclusion}

Open approaches gave approximately the same results of closed ones, but they are more preferable because of the better view of the nasal framework. Regarding to open approaches as results showed there was no significant difference between all parameters post-operatively, each surgeon has to choose the most preferable technique based on his experience and the satisfaction of his patients.

The most recommended technique for correcting the nasal tip deviation was Open book technique because it takes a shorter time and it has an easier approach but there was one single problem which is increasing nasolabial angle (this is not preferable for most female patients of our region) which was solved by using Septal Extension and ExtendedSpreader graft technique.

\section{References}

[1] Ozcan Cakmak, MD. Primary Tip Rhinoplasty and Suture Techniques Article. Professor of Otorhinolaryngology, Acibadem University Kadikoy Hospital, Otorhinolaryngology Department Istanbul, TURKEY. Posted by Guzin Akkuzu on April 2nd, 2011.

[2] Nose Surgery, Patient Health Information, American Academy of Otolaryngology, Head and Neck surgery.http://www.entnet.org/content/nose-surgery Copyright (C) 2014 American Academy of Otolaryngology-Head and Neck Surgery.

\section{Volume 6 Issue 1, January 2017


[3] Carel D. A. Verwoerd ${ }^{*} 1$ and Henriette L. VerwoerdVerhoef $^{1}$, Rhinosurgery in children: developmental and surgical aspects of the growing nose, ${ }^{1}$ Department of Otorhinolaryngology, ErasmusMC, Erasmus University, Rotterdam, The Netherlands. 2010; 9: Doc05. Published online 2011 Apr 27. doi: 10.3205/cto000069

[4] Journal of Graduated Medical Education, Analyzing and Interpreting Data from Likert-Type Scales. Gail $M$ Sullivan, MD, MPH and Anthony R Artino, JR, PhD.

[5] Fatih Ozdogan. Optimal time for intranasal splint removal after septoplasty: a prospective clinical study. Department of OtolaryngologyDerince Research and Training Hospital. European Archives of Oto-RhinoLaryngology. October 2016, Volume 273, Issue 10, pp 3203-3206

[6] S Valentine Fernandes, MBBS, MCPS, FRCSEd, FRACS, FACS, LLB. Complications of Rhinoplasty. Conjoint Senior Clinical Lecturer, Department of Otorhinolaryngology, Newcastle University; Senior Consultant Surgeon, Department of Otorhinolaryngology-Head and Neck Surgery, John Hunter, Warners Bay Private Hospitals, Australia.http://emedicine.medscape.com/article/843439 -overview\#a9

[7] Seyed Mousa Sadr Hosseini1, Mohammad Sadeghi1, Babak Saedi1. Aesthetic and Functional Outcomes of Open versus Closed Septorhinoplasty in Deviated Nose Deformity. 1Otolaryngology Department, Tehran University of Medical Sciences, Tehran, Iran.International Journal of Otolaryngology and Head \& Neck Surgery, 2012, 1, 7-13 http://dx.doi.org/10.4236/ijohns.2012.12002 Published Online August 2012. (http://www.SciRP.org/journal/ijohns)

[8] Yeo NK, et al. AM J Rhinol Allergy. 2009 Sep-Oct. Rhinoplasty to correct nasal deformities in postseptoplasty patients.

[9] Author: Deborah Watson, MD; Chief Editor: Arlen D Meyers, MD, MBA. Septoplasty, Updated in Feb 27, 2015.

[10] Author: A John Vartanian, MD, MS, FACS; Chief Editor: Mark S Granick, MD, FACS. Basic of Closed Rhinoplasty, Updated in Mar 22, 2016

[11]Basic Open Rhinoplasty, http://emedicine.medscape.com/article/1292131treatment\#d9

[12] Rhinoplasty Archive, Extracorporeal septorhinoplasty. 